\title{
PREVALÊNCIA DE ANTICORPOS CONTRA A LINFADENITE CASEOSA EM CRIAÇÕES COMERCIAIS DE OVINOS NO DISTRITO FEDERAL, BRASIL
}

\section{F.B. do Carmo ${ }^{1 *}$, A.S. Guimarães ${ }^{1,2, *}$, R.B. Pauletti ${ }^{1}$, A.P. Lage $^{1 *}$, V.S.P. Gonçalves ${ }^{3}$, R. Meyer ${ }^{4 *}$, R.W.D. Portela ${ }^{4 *}$, A. Miyoshi ${ }^{5}$, V. Azevedo ${ }^{4 *}$, A.M.G. Gouveia ${ }^{1 *}$, M.B. Heinemann ${ }^{1 *}$}

${ }^{1}$ Escola de Veterinária, Departamento de Medicina Veterinária Preventiva, Laboratório de Sanidade de Ovinos e Caprinos, Av. Antônio Carlos, 6627, CEP 30123-970, Belo Horizonte, MG, Brasil. E-mail: address: mabryan@ufmg.br

\section{RESUMO}

O objetivo deste trabalho foi determinar a prevalência de anticorpos contra linfadenite caseosa (LC) em rebanhos ovinos comerciais do Distrito Federal (DF). Foram coletadas 1.028 amostras de soro entre março e junho de 2004, de todas as propriedades (32) do Distrito Federal com pelo menos 20 fêmeas adultas no rebanho. A soroprevalência da linfadenite caseosa foi determinada por ELISA com proteínas secretadas de Corynebacterium pseudotuberculosis. Cinquenta por cento das 32 propriedades apresentaram pelo menos um animal soropositivo para o LC e a prevalência real para animais foi de 44,0\% (IC 95: 41,0; 47,0), portanto, esses dados sugerem que a LC está presente em rebanhos ovinos comerciais no Distrito Federal.

PALAVRAS-CHAVE: Ovinos, linfadenite caseosa, prevalência, Distrito Federal.

\section{ABSTRACT}

PREVALENCE OF ANTIBODIES AGAINST CASEOUS LYMPHADENITIS IN COMMERCIAL SHEEP HERDS IN THE FEDERAL DISTRICT, BRAZIL. The objective of this study was to determinate the seroprevalence of caseous lymphadenitis (CL) in commercial sheep herds in the Federal District, Brazil. One thousand and twenty-eight serum samples were collected, between March and June 2004, from all the properties (32) with at least 20 adult females in the flock. The seroprevalence of caseous lymphadenitis was determined by ELISA with secreted proteins of Corynebacterium pseudotuberculosis. The real prevalence value for the animals was 44.0\% (CI95: 41.0; 47.0 ), and $50.0 \%$ of the 32 herds had at least one animal seropositive for CL. Therefore, these data show that CL is fairly widespread in commercial flocks of sheep in the Federal District.

KEY WORDS: Sheep, caseous lymphadenitis, prevalence, Federal District.

O rebanho ovino brasileiro está concentrado na regiãoSul (IBGE, 2007), onde predomina a produção de lã e mais recentemente carne, seguido da região Nordeste, onde a produção de carne e pele é mais relevante (EmBrapA, 2000). Tanto no Nordeste, que detém o maior rebanho caprino do Brasil, quanto no Sudeste, é frequente a criação concomitante de ovinos e caprinos (PINHEIRO et al., 2000; GUIMARÃES, 2006). Os ovinos são criados, na região Sudeste, principalmente para produção de carne e o sistema de manejo adotado geralmente é extensivo ou semiintensivo (GUIMARÃES, 2006). A criação de ovinos no
Distrito Federal (DF) está direcionada para produção industrial destinada ao consumo de carne (QuESADA et al., 2001).

A linfadenitecaseosa (LC)éuma enfermidade crônica, causada pelo Corynebacterium pseudotuberculosis, caracterizada pelo aparecimento de abscessos em linfonodos tanto superficiais quanto profundos eem órgãos causando depreciação da pelee condenação de carcaças (GUMARÃes et al., 2011). O C. pseudotuberculosis, acomete principalmente pequenos ruminantes ocasionalmente bovinos e equinos e, raramente, o homem e está mundialmente distribuída. Os equi-

${ }^{2}$ Embrapa Gado de Leite, Juiz de Fora, MG, Brasil.

${ }^{3}$ Universidade de Brasília, Brasília, DF, Brasil.

${ }^{4}$ Universidade Federal da Bahia, Laboratório de Imunologia, Salvador, BA, Brasil.

${ }^{5}$ Universidade Federal de Minas Gerais, Instituto de Ciências Biológicas, Laboratório de Genética Celular e Molecular,

Belo Horizonte, MG, Brasil.

*Grupo de Extensão da Pesquisa em Ovinos e Caprinos - GEPOC, Brasil. 
nos desenvolvem linfangite ulcerativa, os bovinos apresentam lesões ulcerativas granulomatosas, que podem ser cutâneas ou viscerais (BAIRD; FONTAINE, 2007). Altas prevalências sorológicas para LC foram detectadas em vários países, tais como $61 \%$ em ovinos na Austrália (MidDLETon et al., 1991), prevalências de até $43 \%$ em ovinos nos EUA (STOOPs et al., 1984) e entre 21 - 36\% em ovinos na província de Quebec, no Canadá (Arsenault et al., 2003).

No Brasil, estima-se quea maioria dos rebanhos de ovinos e caprinos esteja infectada eque a prevalência clínica exceda 30\% dos animais (GARCIA et al., 1987; LANGENEGGER; LANGENEGGER, 1991; FARIA et al., 2004; GUIMARÃEs et al., 2009). De acordo com levantamento sorológico realizado no Estado de Minas Gerais nas espécies caprina e ovina, foram encontradas soroprevalências de 78,9\% em caprinos (SEYFFERT et al., 2010) e 75,8\% em ovinos (Guimarães et al., 2009). SóstenEs et al. (2012) estudando a linfadenite caseosa em ovinos e caprinos no Sertão Paraibano identificaram que 7,7\% (49/640) dos animais apresentavam evidências clínicas de linfadenite caseosa, sendo que 7 ovinos tinham abscessos intactos e em 8 abscessos foram identificados o C. pseudotuberculosis. Em outro estudo, também realizado na Paraíba, Souza et al. (2011) trabalhando com ovinos abatidos em frigorífico determinaram que 15,9\% (236/1466) apresentaram lesões macroscópicas semelhantes à LC.

Diante dos poucos estudos soroepidemiológicos da LC no Brasil, o objetivo deste trabalho foi determinar a soroprevalência da linfadenite caseosa em rebanhos comerciais de ovinos no Distrito Federal.

Foram colhidos, entre marçoejunho de2004,1.028 amostras de 32 propriedades que representavam o total de criatórios do DF que tinham a ovinocultura como principal atividade e pelo menos 20 matrizes no rebanho. Estas propriedades localizavam-se nos Núcleos Rurais do Gama, Programa de Assentamento Dirigido (PAD-DF), Jardim, Tabatinga, Rio Preto, Taquara, Pipiripau, Planaltina e Sobradinho.

A soroprevalência para linfadenite caseosa foi determinada através de ELISA indireto realizado segundo SEYFFERT et al. (2010) com sensibilidade diagnóstica de 93,5\% e especificidade de 98,5\%. A soroprevalência e intervalos de confiança foram calculados usando o programa WinEpiscope ${ }^{\circledR}$ 2.0. Para o cálculo foi considerada a prevalência esperada de 75,8\% encontrada em Minas Gerais (GuIMARÃEs et al., 2009). A prevalência real (Pr) para animais foi calculada conforme NoordhuIZEN et al. (1997) e BENNETT et al. (1991), utilizando a seguinte fórmula: $\mathrm{Pr}=(\mathrm{Pa}$ + Esp - 1) / (Sen + Esp - 1), onde: PR = prevalência real; Sen $=$ sensibilidade do teste; $\mathrm{Pa}=$ prevalência aparente e Esp = especificidade do teste.

No DF foi verificada uma soroprevalência de 42,1\%, com prevalência real de 44,0\% (IC 95: 41,0; $47,0)$ para animais, sendo que $50 \%$ das proprie- dades concentravam os animais soropositivos. A alta prevalência da LC, tanto em animais como em propriedades também foi observada por GUIMARÃES et al. (2009), que encontraram, em 642 ovinos distribuídos em 97 propriedades, positividade de $75,8 \%$ em animais e $95,9 \%$ de propriedades, utilizando o mesmo teste sorológico do presente trabalho. Em levantamento da LC realizado por GuIMARÃES (2006) por meio de questionário aplicado aos responsáveis pelas mesmas fazendas com ovinos em Minas Gerais que participaram do levantamento sorológico apenas $6,1 \%$ dos proprietários observaram a doença, demonstrando desconhecimento da presença do agente nos rebanhos. Já TiNÔco (1983), em estudo epidemiológico feito por questionário na Bahia, detectaram 36,5\% de fazendas positivas, essa maior positividade pode ser devido ao tipo de criação (extensiva) e vegetação (cerrado, caatinga) que pode favorecer uma maior disseminação da LC nesse Estado. Em estudos realizados na Paraíba, encontrou-se prevalências mais baixas, entre 7 a $15 \%$, mas isto se deve principalmente por se tratar de observação de lesões compatíveis a LC que pode levar a uma subestimativa da prevalência real. Mas a maior parte das lesões é devido a infecção por $C$. pseudotuberculosis (SouzA et al., 2011; SósTENES et al., 2012), demonstrando a importância deste agente na patologia dos abscessos.

Os resultados obtidos tanto na sorologia realizada em Minas Gerais (Guimarães et al., 2009) quanto na realizada no $\mathrm{DF}$, apontaram tendência de manutenção da alta frequência de soropositividade animal e de propriedades. Além disso, esses resultados demonstram o desconhecimento em relação à importância econômica da presença do agente nos rebanhos ovinos nacionais, bem como da necessidade de implantação de medidas efetivas de controle em nível de propriedade e de fronteiras interestaduais, de forma a controlar e disseminação do agente entre rebanhos e entre Estados além de viabilizar o fornecimento de matéria prima (cordeiros) em quantidade e qualidade requeridas pelos mercados interno e externo.

Em relação aos sistemas de exploração, foram encontrados uma maior predominância do sistema extensivo $(48,4 \%)$. A alta prevalência encontrada pode ser explicada pelos tipos de manejo predominantes no DF que, segundo GUIMARÃEs et al. (2009), podem contribuir para maior disseminação do agente em função de menor número de inspeções clínicas minuciosas realizadas pelos responsáveis pelos rebanhos. Além disso, Sóstenes etal. (2012) identificaram que deixar o abscesso romper naturalmente está as-sociado a um maior risco de ocorrência da infecção, isto é explicado pelo contato direto eindireto, como pastagens, instalações e utensílios, contaminadas com as secreções purulentas dos abscessos. Animais introduzidos nas 
fazendas devem ser rigorosamente examinados antes da compra, testados sorologicamente e mantidos em quarentena, visto que muitos animais soropositivos não apresentam sinais clínicos. A adoção dessas medidas deve-se ao fato de a metade das fazendas amostradas no DF concentrarem todos os animais soropositivos, ou seja, ainda existem rebanhos com baixa prevalência da doença e que necessitam de medidas eficazes de prevenção e controle em relação ao C. pseudotuberculosis. Além disso, as propriedades do DF são compradoras de animais e estes são oriundos principalmente dos estados do Nordeste brasileiro, onde estudos epidemiológicos têm demonstrado uma alta positividade dos animais desta região (TinôCo, 1983; BAKer; Souza, 1987; Pinheiro et al., 2000; CARMO et al., 2009).

Os rebanhos amostrados eram constituídos, em sua maioria, de animais puros $(80,65 \%)$ e mestiços $(19,35 \%)$ da raça Santa Inês. Segundo Guimarães et al. (2009), a raça não constitui fator de risco para infecção de LC, mas é possível inferir que animais de pelo curto, como os puros ou mestiços da raça Santa Inês, estão mais predispostos a ocorrência de lesões de pele provocadas por fatores mecânicos do que animais de raças lanadas, seja no manejo dentro de instalações ou lesões causadas pela vegetação seca ou espinhosa, comuns em períodos de estiagem.

A alta prevalência de animais soropositivos para LC sugere ampla disseminação da doença no DF e medidas de controle e de melhorias no manejo sanitário dos rebanhos devem ser adotadas para reverter este quadro.

Este experimento foi realizado conforme os princípios éticos da experimentação animal estabelecidos pela Comissão de Ética da Faculdade de Medicina Veterinária e Zootecnia da Universidade de São Paulo (n ${ }^{\circ}$ 488/2004 de 25/10/2005).

\section{AGRADECIMENTOS}

Agradecemos ao Conselho Nacional de Desenvolvimento Científico e Tecnológico (CNPq), Fundação de Amparo à Pesquisa do Estado de Minas Gerais (FAPEMIG), à Fundação de Ensino e Pesquisa em Medicina Veterinária e Zootecnia (FEP-MVZ). APL e MBH possuem bolsa produtividade do CNPq.

\section{REFERÊNCIAS}

ARSENAULT, J.O.; GIRARD, C.; DUBREUIL, P.; DAIGNAULT, D. O.; GALARNEAU, J.-R.; BOISCLAIR, J.; SIMARD, C.; BÉLANGER, D. Prevalence of and carcass condemnation from Maedi-Visna, paratuberculosis and caseous lymphadenitis in culled sheep from Quebec,
Canada. Preventive Veterinary Medicine, v.59, p.67-81, 2003.

BAIRD, G.J.; FONTAINE, M.C. Corynebacterium pseudotuberculosis and its role in ovine caseous lymphadenitis. Journal of Comparative Pathology, v.137, p.179-210, 2007.

BAKER, G.; SOUZA NETO, J. Características gerais da caprinocultura leiteira no estado do Rio Grande do Norte. Sobral: Embrapa-CNPC, 1987. (Embrapa-CNPC. Boletim de Pesquisa, n.9).

BENNETT, S.; WOODS, T.; LIYANAGE, W.M.; SMITH, D.L. A simplified general method for cluster sample surveys of health in developing countries. World Health Statistics Quartely, v.44, n.3, p.98-106, 1991.

CARMO, F.B.; GOUVEIA, A.M.G.; GUIMARÃES, A.S.; PAULETTI, R.B.; LAGE, A.P.; FERREIRA, F.; PORTELA, R.W.D.; PINHEIRO, R.R.; AZEVEDO, V.A.C.; HEINEMANN, M.B. Soroprevalência da linfadenite caseosa em caprinos em propriedades do Estado do Ceará. In: CONGRESSO BRASILEIRO DE MICROBIOLOGIA, 25., 2009, Porto de Galinhas, PE. Resumos. Porto de Galinhas: 2009.

EMBRAPA-CNPC. Brasil. Plano diretor da embrapa caprinos e ovinos. Sobral: Centro Nacional de Pesquisa de Caprinos, 2000. 36p.

FARIA, G.A. de; MORAIS, O.R. de; GUIMARÃES, P.H.S. Análise da Ovinocaprinocultura no Norte e Nordeste de Minas Gerais. Belo Horizonte: SEBRAEMG, FAEMG, EMATER, 2004. 122p.

GARCIA, M.; ARAÚJO, W.P.; CARVALHO, V.M.; COSTA, E.O. Isolamento e identificação do Corynebacterium pseudotuberculosis em ovinos e caprinos nos Estados de São Paulo e Minas Gerais. Revista da Faculdade de Medicina Veterinária e Zootecnia da Universidade de São Paulo, v.24, p.23-25, 1987.

GUIMARÃES, A.S. Caracterização da Caprinovinocultura em Minas Gerais. 2006. 84p. Dissertação. (Mestrado em Medicina Veterinaria Preventiva e Epidemiologia) Escola de Veterinária da Universidade Federal de Minas Gerais, Belo Horizonte, 2006.

GUIMARÃES, A.S.; SEYFFERT, N.; PORTELA, R.W.D.; MEYER, R.; CARMO, F. B.; CRUZ, J.C.M.; LAGE, A.P.; HEINEMANN, M.B.; AZEVEDO, V.A.C.; GOUVEIA, A.M.G. Caseous lymphadenitis in sheep flocks of the state of Minas Gerais, Brazil: Prevalence and management surveys. Small Ruminant Research, v.87, p.86-91, 2009.

GUIMARÃES, A.S.; CARMO, F.B.; PAULETTI, R.B.; SEYFFERT, N.; RIBEIRO, D.; LAGE, A. P.; HEINE-

MANN, M.B.; MIYOSHI, A.; AZEVEDO, V.; GOUVEIA, A.M.G. Caseous lymphadenitis: epidemiology, diagnosis, and control. The IIOAB Journal, v.2, p.33-43, 2011. 
IBGE - INSTITUTO BRASILEIRO DE GEOGRAFIA E ESTATÍSTICA. Censo Agropecuário 2007. Censo Agropecuário. Disponível em: <http://www.ibge.gov.br> Acesso em: 15 set. 2010.

\section{LANGENEGGER, C.H.; LANGENEGGER, J. Monitora-} mento sorológico e alérgico da infecção por Corynebacterium pseudotuberculosis em caprinos. Pesquisa Veterinária Brasileira, v.11, n.1/2, p.31-34, 1991.

MIDDLETON, M.J.; EPSTEIN, V.M.; GREGORY, G.G. Caseous lymphadenitis on Flanders Island: prevalence and management surveys. Australian Veterinary Journal, v.68, p.311-312, 1991.

NOORDHUIZEN, J.P.T.M.; FRANKENA, K.; VAN DER HOOFD, C.M.; GRAAF, E.A.M. Application of quantitative methods in veterinary epidemiology. Wageningen:

Wageningen Pers, 1997. 445p.

PINHEIRO, R.R.; GOUVEIA, A.M.G.; ALVES, F.S.F.; HADDAD J.P.A. Aspectos Epidemiológicos da Caprinocultura Cearense. Arquivo Brasileiro Medicina Veterinária e Zootecnia, v.52, n.5, p.1-14, 2000.

QUESADA, M.; MacMANUS, C.; COUTO, F.A.D. Tolerância ao calor de duas raças de ovinos deslanados no Distrito Federal. Revista Brasileira de Zootecnia, v.30, n.3, p.1021-1026, 2001.

SEYFFERT, N.; GUIMARÃES, A.S.; PACHECO, L.G.C.; PORTELA, R.W; BASTOS, B.L.; DORELLA, F.A.; HEINEMANN, M.B.; LAGE, A.P.; GOUVEIA, A.M.G.; MEYER, R.; MIYOSHI, A.; AZEVEDO, V.N. High seroprevalence of caseous lymphadenitis in Brazilian goat herds revealed by Corynebacterium pseudotuberculosis secreted proteins-based ELISA. Research in Veterinary Science, v.88, n.1, p.50-55, 2010.

SÓSTENES J.; ANDRADE, L.; AZEVEDO, S.S.; TELES, J.A.A.; HIGINO, S.S.S.; AZEVEDO, E.O.. Ocorrência e fatores de risco associados à infecção por Corynebacterium pseudotuberculosis em caprinos e ovinos do semiárido paraibano. Pesquisa Veterinária Brasileira, v.32, n.2, p.116-120, 2012.

SOUZA, M.F.; CARVALHO, A.Q.; GARINO JUNIOR, F; RIET-CORREA, F. Linfadenite caseosa em ovinos deslanados abatidos em um frigorífico da Paraíba. Pesquisa Veterinária Brasileira, v.31, n.3, p.224-230, 2011.

STOOPS, S.G.; RENSHAW, H.W.; THILSTED, J.P. Ovine caseous lymphadenitis: disease prevalence, lesion distribution, and thoracic manifestations in a population of mature culled sheep from western United States. American Journal Veterinary Research, v.45, p.557-561, 1984.

TINÔCO, A.L.A. Diagnóstico de situação da ovino/caprinocultura em três municípios do sertão baiano - Euclides da Cunha, Quijingue, Monte Santo - Bahia, 1981/1982. In: SEMINÁRIO EM MEDICINA VETERINÁRIA PREVENTIVA E EPIDEMIOLOGIA, 1983, Belo Horizonte. Resumos. Belo Horizonte: Escola de Veterinária da UFMG, 1983. p.13.

Recebido em 6/2/11

Aceito em 8/5/12 